\title{
Mechanical Properties of Acrylonitrile-Butadiene Rubber (NBR)/Poly (Vinyl Chloride) Resin Binary Blend
}

\author{
Ali I. Al-Mosawi1 ${ }^{*}$, Mohammed H. Al-Maamor², Kálmán Marossy¹, Haider A. Yasser², \\ Shaymaa Abbas Abdulsada ${ }^{1}$
}

${ }^{1}$ Faculty of Materials Science and Engineering, University of Miskolc, Miskolc, Hungary

${ }^{2}$ College of Engineering Materials, University of Babylon, Hilla, Iraq

Email: *aliibrahim76@yahoo.com

How to cite this paper: Al-Mosawi, A.I., Al-Maamor, M.H., Marossy, K., Yasser, H.A. and Abdulsada, S.A. (2019) Mechanical Properties of Acrylonitrile-Butadiene Rubber (NBR)/Poly(Vinyl Chloride) Resin Binary Blend. Open Access Library Journal, 6: e5956.

https://doi.org/10.4236/oalib.1105956

Received: November 25, 2019

Accepted: December 22, 2019

Published: December 25, 2019

Copyright () 2019 by author(s) and Open Access Library Inc.

This work is licensed under the Creative Commons Attribution International License (CC BY 4.0).

http://creativecommons.org/licenses/by/4.0/

\begin{abstract}
Changes in the mechanical properties of Acrylonitrile-Butadiene Rubber (NBR)/Poly (vinyl chloride) resin binary blend were investigated. Poly (vinyl chloride) resin additives were within range $(0-70)$ wt.\%, and the measured mechanical properties included tensile strength, elongation, and compression strength. The obtained results showed that the tensile and elongation value of NBR starts to decrease with the addition of PVC resin to reach the maximum decrease at $70 \%$, where the tensile strength was reduced by $85.23 \%$ and elongation by $90.44 \%$. On the other hand, the compression strength of NBR improved after PVC resin addition and the optimum improvement was $82.55 \%$ at $70 \%$ PVC resin.
\end{abstract}

\section{Subject Areas \\ Composite Material, Material Experiment}

\section{Keywords}

Binary Blend, NBR, PVC Resin, Mechanical Properties

\section{Introduction}

In recent decades, researchers have been working to develop new properties of polymeric materials or improve their original properties, and this development or enhancement is not dependent on the fillers [1] [2] [3] [4], but by the formation of a mixtures between a group of polymers to form a hybrid polymeric material, which is known as blends [5] [6] [7] [8] [9]. The blends may be a poly- 
mer-polymer or a polymer-rubber or rubber-rubber, and it can also be binary, ternary or quaternary depending on the application in which the hybrid blend is used (such as electrical, mechanical, chemical application, etc) [10]-[15]. The critical parameter determining the success or failure of the polymeric blend (from the point of view of the properties obtained) is the degree of miscibility between the blend's components [16] as shown in Figure 1 which represents the miscibility of a binary polymeric system [17]. And in order to obtain an optimal hybrid blend all components must be fully miscible and the whole degree of miscibility depends on the type of polymers mixed [18] [19] [20], the percentages of mixed polymers where they should be not high, free energy, and the degree of glass transition where any defect in these factors will occur separation between phases [10] [17] [21] [22].

Rubber blends are used with other polymers in many engineering applications, which include: hose cover linings, footwear, conveyor belt covers, cable jackets, gaskets, cellular products, etc. [23]. It has been found through research that Acrylonitrile-Butadiene Rubber has a plasticizing effect on poly(vinyl chloride), so it can be used together to produce insulated cables with high insulating efficiency, also poly (vinyl chloride) additives will develop other properties of Acrylonitrile-Butadiene Rubber such as chemical resistance, thermal aging, and abrasion resistance [24] [25] [26] [27].

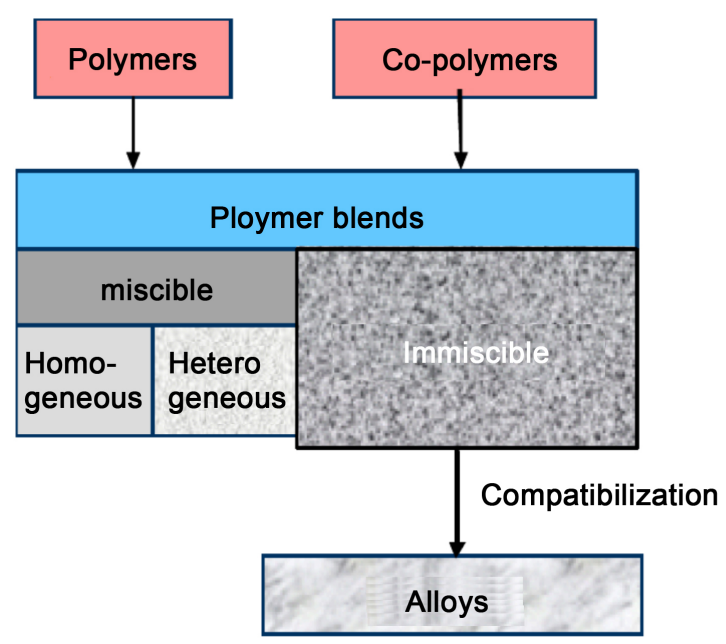

Figure 1. Miscibility of a binary polymeric system [17].

\section{Experiment}

\subsection{Materials}

1) Acrylonitrile-Butadiene Rubber (NBR-30\% AN) supplied by Jingjiang Concord New Materials Technology Co., Ltd., China.

2) Poly (vinyl chloride) resin type S-5070 with trademark Ongrovil ${ }^{\Phi}$ which produced and supplied by Borsod ChemZrt., Hungary.

3) Zinc oxide was supplied by the Turkish company Saha Metal San. Tic. Ltd. Şti. 
4) Stearic acid supplied by the Chinese company Hefei TNJ Chemical Industry Co., Ltd.

5) Carbon black 660 supplied by the Chinese company Tianjin Lizheng International Trade Co., Ltd.

6) Accelerator MBTS supplied by Richest Group, China.

7) Sulfur supplied by the Chinese company Leader Technologies Co., Ltd.

\subsection{The Processing of Materials}

Eight blends were prepared by using laboratory roll mill machine type Schwabenthan as sheets found at Borsod ChemZrt. with $0.4 \mathrm{~mm}$ thickness. Then, these sheets were pressed by using hydraulic press type Bürkle found at BorsodChemZrt. with processing conditions at 300 and 20 bar pressure and $150^{\circ} \mathrm{C}$ temperature to form a square-shape plate. The last step is to cut these sheets into test samples.

\subsection{Preparation of Samples}

The compression strength samples were prepared according to ASTM D 1229 standards [28] and the samples of tensile strength prepared according to ASTM D412-16 standards [29].

\subsection{Mechanical Testes}

Instron 5560 instrument at University of Miskolc was used to perform the tensile test and calculate the tensile strength. In order to estimate the compression strength, a compression tester at University of Miskolc was used for this purpose (Table 1).

\section{Results and Discussion}

The results obtained from the tensile test are shown in Figure 2, which represents the tensile strength of the binary blend as a function of the poly (vinyl chloride) resin weight percentage. From this figure, we notice that the tensile strength of Acrylonitrile-Butadiene Rubber begins to decrease once the poly (vinyl chloride) resin is added and form the binary blend and the reduction in tensile strength increases as the proportion of the poly (vinyl chloride) resin addition

Table 1. The materials used in NBR-PVC blends.

\begin{tabular}{cc}
\hline Material & Wt.\% \\
\hline NBR & 100 (Decreases gradually as the PVC percentage increases by 10 g per blend) \\
PVC & $0-70$ \\
Carbon black 660 & 40 \\
MBTS & 0.7 \\
Sulfur & 1.5 \\
Zinc oxide & 3 \\
Stearic acid & 1 \\
\hline
\end{tabular}




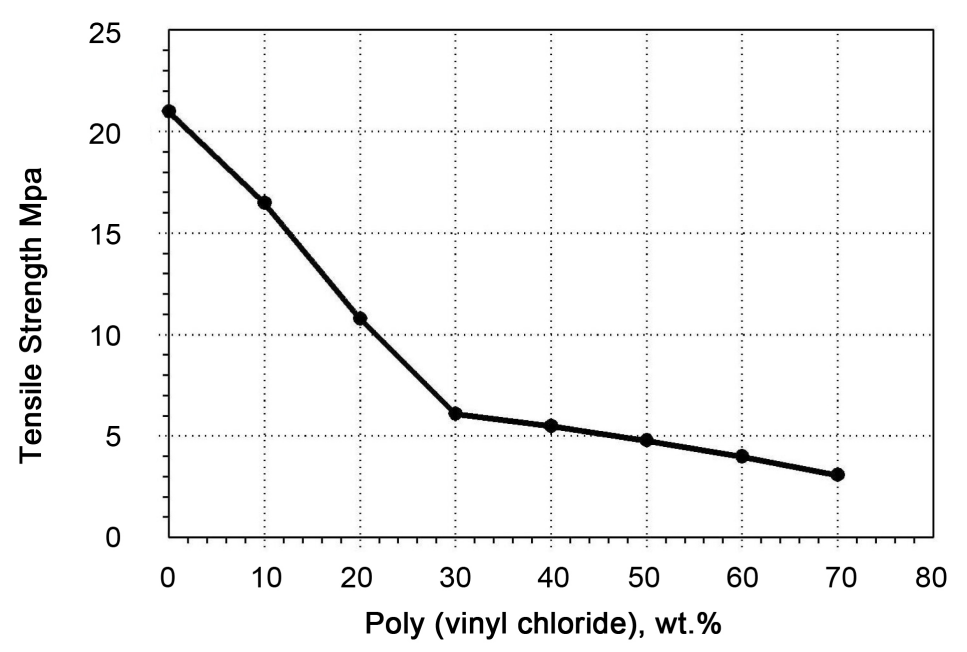

Figure 2. Tensile strength of NBR-PVC binary blend.

increases. The reason for this behavior is due to the polymer restricts the elasticity of Acrylonitrile-Butadiene Rubbermolecular chains so that its movement becomes not free under stress and the distance between them will increase as a result of lack of crosslinking.

On the other hand, the elongation of Acrylonitrile-Butadiene Rubber decreases with the addition of the poly (vinyl chloride) resin and this behavior can be seen in Figure 3 which represents elongation of NBR-PVC binary blend. The reason for this state is that the applied stresses will be concentrated mainly on certain molecular chains which are (C-C, C-H and C-CL), while the C-S and S-S bonds will be exposed to a small fraction of stresses, resulting in ruptures in bonds where stresses are highly concentrated and begin to break.

In the case of compression strength for rubber, it improved after the addition of the poly (vinyl chloride) resin and can be clearly distinguished from Figure 4 which represents the compression strength of NBR-PVC binary blend. It is known that the rate of permanent deformation in polymers is higher than rubber after the removal of applied load, so when the poly (vinyl chloride) resin is added to Acrylonitrile-Butadiene Rubber, the polymer will subject to a permanent deformation higher than rubber, which will increase the compression strength of the binary blend.

\section{Conclusion}

Poly (vinyl chloride) resin reduces the elasticity of Acrylonitrile-Butadiene Rubber molecular chains, causing stresses to concentrate on certain chains resulting break down of these chains, and significantly reduced tensile strength and elongation of the binary blend. On the other hand, the compressive strength of Acrylonitrile-Butadiene Rubber increases with the addition of poly (vinyl chloride) resin due to the different permanent deformation between them as poly (vinyl chloride) resin is exposed to the higher permanent deformation compared to Acrylonitrile-Butadiene Rubber. 


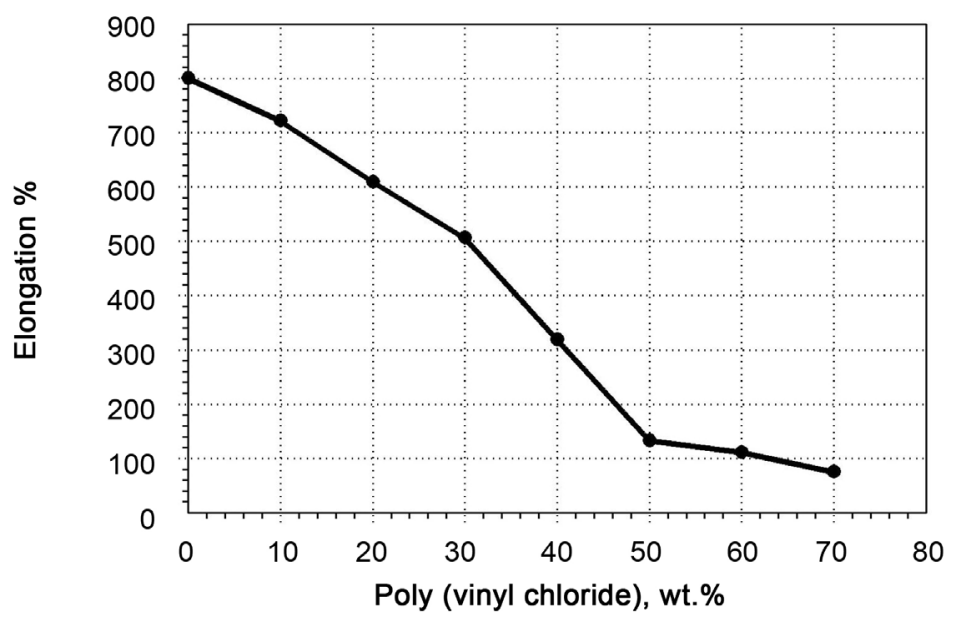

Figure 3. Elongation of NBR-PVC binary blend.

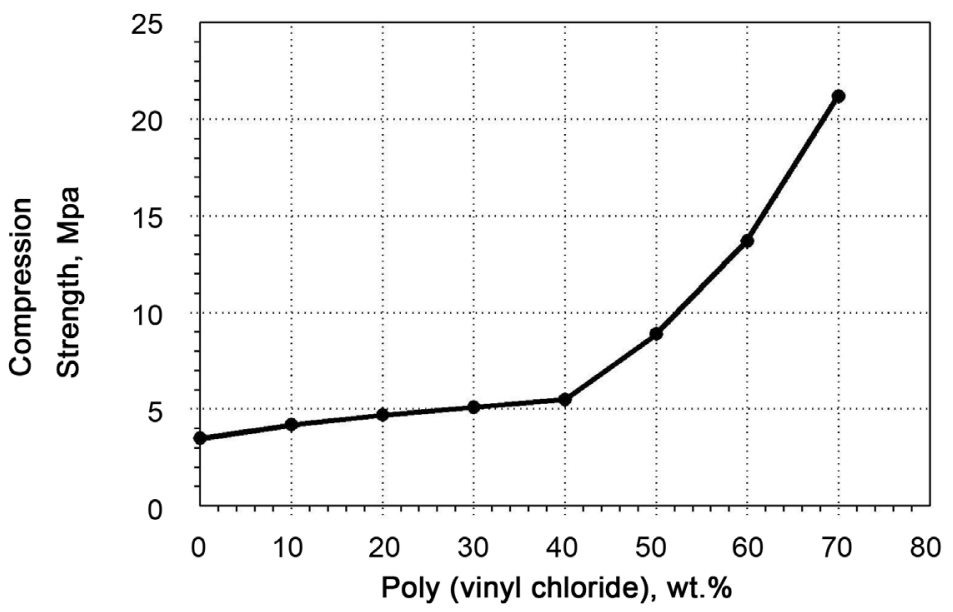

Figure 4. Compression strength of NBR-PVC binary blend.

\section{Acknowledgments}

After completing our research, we must extend our thanks and appreciation to those who helped and they are Krisztina Tózsa at Borsod Chem Zrt., Hungary; and Tasnádi Ildikó at Institute of Ceramic and Polymer Engineering, University of Miskolc, Hungary.

\section{Conflicts of Interest}

The authors declare no conflicts of interest regarding the publication of this paper.

\section{References}

[1] Al-Mosawi, A.I., Hashim, A.A. and Al-Maamori, M.H. (2019) Production of High Performance Mountings by Using Rubber-Polymer Waste. Open Access Library Journal, 6, 1-6. https://doi.org/10.4236/oalib.1105368

[2] Al-Maamori, M.H. and Al-Mosawi, A.I. (2018) Polymers and Composite Materials Technology. Dar Safa for Publishing and Distributing, Jordan. 
[3] Al-Maamori, M.H., Al-Mosawi, A.I. and Abdulsada, S.A. (2018) Effect of Novolac Nanoparticles Additions on Specific Gravity of NBR/CR Blends. MATEC Web of Conferences, 178, Article ID: 04001. https://doi.org/10.1051/matecconf/201817804001

[4] Kargarzadeh, H., Ahmad, I. and Abdullah, I. (2017) Mechanical Properties of Epoxy/ Rubber Blends, In: Parameswaranpillai, J., Hameed, N., Pionteck, J. and Woo, E., Eds., Handbook of Epoxy Blends, Springer, Cham, 279-314.

https://doi.org/10.1007/978-3-319-40043-3_11

[5] Yasser, H., Al-Maamori, M.H. and Al-Mosawi, A. (2014) Effects of Polyvinyl Chloride Addition on Swelling Resistance of Nitril Rubber. Research Journal of Recent Sciences, 3, 209-211.

[6] Al-Maamori, M.H., Al-Mosawi, A.I. and Abdulsada, S.A. (2017) Mechanical Properties of Hybrid Elastomer Blends. Journal of Thin Films, Coating Science Technology and Application, 4, 13-17.

[7] Al-Mosawi, A.I., Al-Maamori, M.H. and Marossy, K. (2019) Rheological Properties of NBR/CR Blends as a Function of Silicon Dioxide Grain Size Gradation. Journal of Silicate Based and Composite Materials, 71, 43-45. https://doi.org/10.14382/epitoanyag-jsbcm.2019.8

[8] Al-Maamori, M.H. and Al-Mosawi, A.I. (2017) The Impact of Novolac Wt.\% Nanoadditives on Rheological Properties of NBR/CR Blends. International Journal of Fracture and Damage Mechanics, 3, 19-23.

[9] Al-Maamori, M.H., Al-Mosawi, A.I., Yasser, H.A. and Jabbar, Z. (2014) Mechanical Properties of Acrylonitrile-Butadiene Rubber Reinforced by Polyvinyl Chloride Particles. Proceedings of 1 st National Conference for Engineering, Engineering College, University of Mustansiriyah, Iraq, 26-27 March 2014.

[10] Bartczak, Z. and Galeski, A. (2014) Mechanical Properties of Polymer Blends. In: Utracki, L. and Wilkie, C., Eds., Polymer Blends Handbook, Springer, Dordrecht, 1203-1297. https://doi.org/10.1007/978-94-007-6064-6_13

[11] Al-Maamori, M.H., Al-Mosawi, A.I. and Abdulsada, S.A. (2017) The Rheological Effect of $\mathrm{SiO}_{2}$ Nanoparticles Additives for NBR/CR Blends. Journal of Catalyst and Catalysis, 4, 1-4.

[12] Al-Maamori, M.H., Al-Mosawi, A.I. and Abdulsada, S.A. (2016) Rheological Behavior of Rubber Blends. 2nd International Conference on Innovative Trends in Engineering, Science and Management (ICITESM-16), YMCA , Jai Singh Road, Delhi, India, 19 November 2016.

[13] Liu, X.Q., Al-Mosawi, A.I. and Li, B. (2014) Materials Science and Advanced Technologies in Manufacturing II: Selected. The 4th International Conference on Materials Science and Engineering (ICMSE2014), Jiujiang, China, 27-28 December 2014.

[14] Corish, P.J. (1985) Rubber-Rubber Blends, In: Walsh, D.J., Higgins, J.S. and Maconnachie, A., Eds., Polymer Blends and Mixtures, NATO ASI Series (Series E: Applied Sciences), Volume 89, Springer, Dordrecht, 245-265. https://doi.org/10.1007/978-94-009-5101-3_12

[15] Al-Mosawi, A.I., Ali, M.M. and Mohmmed, J.H. (2012) Experimental Approach to Mechanical Properties of Natural Rubber Mixing with Calcium Carbonate Powder. International Journal of Physical Sciences, 7, 6280-6282.

[16] Al-Maamori, M.H., Al-Mosawi, A.I. and Saadon, L.M. (2013) Effect of Physical Additives of Shells Powder on Mechanical Properties of Natural Rubber. International Journal of Technical Research and Applications, 1, 31-33.

[17] TA Instruments (1997) Mixing Rules for Complex Polymer Systems. Technical Re- 
port No.RH095, 1-8.

[18] Hamad, K., Kaseem, M., Ayyoob, M., Joo, J. and Deri, F. (2018) Polylactic Acid Blends: The Future of Green, Light and Tough. Progress in Polymer Science, 85, 83-127. https://doi.org/10.1016/j.progpolymsci.2018.07.001

[19] Al-Mosawi, A.I. (2013) Effect of Shells Powder Filler Additives on Hardness and Tensile Strength Properties of Natural Rubber. Journal of Materials Physics and Chemistry, 1, 35-36. https://doi.org/10.12691/jmpc-1-3-2

[20] Avramova, N. (1998) Polymer Additives: The Miscibility of Blends. In: Pritchard, G., Ed., Plastics Additives, Polymer Science and Technology Series, Volume 1, Springer, Dordrecht, 513-518. https://doi.org/10.1007/978-94-011-5862-6_56

[21] Al-Maamori, M.H., Al-Mosawi, A.I. and Yasser, H.A. (2014) Mechanical Behavior of NBR-PVC Mixture after Immersion in Different Media. International Journal of Advanced Research in Engineering and Technology, 5, 34-39.

[22] Al-Maamori, M.H., Al-Mosawi, A.I., Abdulsada, S.A. and Yasser, H.A. (2015) Rheological Properties of NBR-PVC Blend. EC Chemistry, 1, 25-29.

[23] Gomes, A.C.O., Soares, B.G., Oliveira, M.G., Oliveira, M.F.L. and Paranhos, C.M. (2009) PA6/NBR Blends: Improvement of Processability and Mechanical Properties. e-Polymers, 9, 1-13. https://doi.org/10.1515/epoly.2009.9.1.1270

[24] Shokri, A.A., Bakhshandeh, G. and Farahani, T.D. (2006) An Investigation of Mechanical and Rheological Properties of NBR/PVC Blends: Influence of Anhydride Additives, Mixing Procedure and NBR Form. Iranian Polymer Journal, 15, 227-237.

[25] Ishiaku, U.S., Lim, F.S., Ishak, Z.A. and Senake Perera, M.C. (1999) Mechanical Properties and Thermooxidative Aging of a Ternary Blend, PVC/Enr/Nbr, Compared with the Binary Blends of Pvc. Polymer-Plastics Technology and Engineering, 38, 939-954. https://doi.org/10.1080/03602559909351623

[26] Alalkawi, H.J.M., Hantoosh, Z.K. and Majid, R.H. (2010) The Tensile and Fatigue Properties of Vulcanized Natural Rubber under Ambient Temperatures. Diyala Journal of Engineering Sciences, 3, 16-24.

[27] Ahmad, A., HjMohd, D. and Abdullah, I. (2004) Mechanical Properties of Filled NR/LLDPE Blends. Iranian Polymer Journal, 13, 173-178.

[28] ASTM D1229-03 (2015) Standard Test Method for Rubber Property-Compression Set at Low Temperatures. ASTM International, West Conshohocken, PA. https://doi.org/10.1520/D1229-03R15

[29] ASTM D412-16 (2016) Standard Test Methods for Vulcanized Rubber and Thermoplastic Elastomers-Tension. ASTM International, West Conshohocken, PA. https://doi.org/10.1520/D0412-16 